\title{
Procedimientos en la lexicalización Científico- TÉCNICA DE LOS SONIDOS: ESTUDIO CONTRASTIVO ESPAÑOL-INGLÉS
}

\author{
Verónica Vivanco Cervero \\ Universidad Politécnica de Madrid \\ veronicacruz.vivanco@upm.es
}

Resumen: Este artículo se centra en la acuñación léxica de algunos sonidos del ámbito de la ciencia y la tecnología en español e inglés. Se han elegido voces de alto uso en dicho ámbito: canto, chasquido/parásito, craqueo, galería de susurros/sala de murmullos, tintineo/castañeteo, ululación/chillido del búho, y zumbido, y sus correlatos ingleses singing/humming, hash/parasite, cracking, whispering gallery, chatter, hoot y hum, que muestran un mayor número de variantes sinónimas en español. Las estadísticas muestran que las tipologías de acuñación en lo relativo a la captación de sonido en ambos idiomas están muy fragmentadas (ametáforas, onomatopeyas, metáforas, personificaciones, animalizaciones y variantes mixtas) y que las onomatopeyas tienen una mayor presencia en inglés (66\%) que en español (42\%), quien suele heredarlas del primero como idioma acuñador de neologismos técnicos.

Palabras clave: acuñación léxica, onomatopeya, metáfora, personificación.

Tittle: Procedures in the scientific and technical coining of sounds: Spanish-English contrastive study

\begin{abstract}
This article focuses on the lexical coining of the sounds in the field of science and technology in Spanish and English. Words of high use in the aforementioned field have been chosen, such as canto, chasquido/parásito, craqueo, galería de susurros/ sala de murmullos, tintineo/castañeteo, ululación/chillido del búbo, y zumbido y sus correlatos ingleses singing/humming, hash/ parasite, cracking, whispering gallery, chatter, hoot, and hum, which show a greater number of synonyms in Spanish. The statistics show that the typologies of lexical coining in relation to the capture of sounds in both languages are fragmented (ametaphors, onomatopoeias, metaphors, personifications, animalizations and hybrid tipologies) and that onomatopoeias have a greater presence in English (66\%) than in Spanish (42\%), language which adopts the technicisms coined by the first.
\end{abstract}

Keywords: lexical coining, onomatopoeia, metaphor, personification. 


\section{INTRODUCCIÓN}

En lingüística se estudia el término lexicalización tomado como acuñación o formación de palabras necesarias debido a un vacío lingüístico que no casa un significante con un significado. Como sostiene Elvira (2006: 4), «Más en concreto, lexicalización es el proceso por el cual una expresión, que previamente se obtenía o refería acceso por medios gramaticales o analíticos, se archiva como un bloque en la memoria o diccionario mental y se utiliza de manera global, sin necesidad de análisis previo», lo que resulta en un orden más estricto o fijo que el de la gramaticalización (Moreno Cabrera, 1998: 79). Un fenómeno similar es el de la onomaturgia, la operación de dar nombre a las cosas por medio de acuñaciones léxicas que calan en los hablantes (Álvarez de Miranda, 2009), como sería el caso del compuesto Big Bang, acuñado irónicamente por Fred Hoyle en marzo de 1949 para rebatir la teoría de George Gamow sobre el origen del universo.

Sin embargo, el recurso que analizamos presenta una perspectiva diferente, porque en él no se muestra la incidencia de bloques léxicos ni de onomaturgias o bautismos personalizados en la acuñación de términos. La acuñación léxica de sonidos, procedimiento no demasiado prolífico en el vocabulario de un idioma, en principio, se encuentra muy ligada a la onomatopeya, sin embargo tal recurso no parece ser objeto de abundantes investigaciones. Existe una gran falta de estudio de la onomatopeya por su aparente imposibilidad de acoplamiento exacto fonético-gráfico, por constituir una forma de expresión infantil, desdibujada y de difícil acoplamiento entre diferentes idomas . Bueno (1994: 18) sostiene que la onomatopeya tiene un gran carácter fonosimbólico, por adoptar un esquema articulatorio cercano al del sonido primigenio. Además, no cualquier intento de captación de sonido es una onomatopeya, sino solo el que está acuñado y registrado, es decir, aquel cuya morfología se encuentra integrada en el acervo de un idioma. Por ejemplo, la expresión [uff, uff] para expresar el cansancio o el esfuerzo no representa una palabra en un idioma, por lo que no es parte integrante de su vocabulario ni una onomatopeya, tan solo un intento de aproximarse a ella perteneciente a la paralingüística. No obstante, el tiempo y el grado de uso por parte de los hablantes son los que acaban lexicalizando las expresiones.

A la disparidad de criterios en cuanto a la integración de una onomatopeya por parte de los hablantes de una misma lengua, se une la diferente captación fonética de los hablantes de otros idiomas, por lo que el asunto se vuelve más peliagudo. No obstante, cabe señalar que existen notas comunes, aunque también discordancias, entre los diferentes idiomas en el registro de sonidos y ruidos procedentes de cualquier fuente natural o artificial. Por ejemplo, el ruido del claxon en español suena como 
[piiii] mientras que en inglés lo reflejan como [honk] lo que supone onomatopeyas completamente opuestas. Lo anterior demuestra que no todas las creaciones léxicas de la ciencia y la tecnología en español son calcos del inglés, sino que el castellano mantiene un acervo propio e independiente. Además, los diccionarios no ofrecen datación del uso de las voces, y, en el caso de aparecer una fecha de primer registro escrito de estas, solo aportan en exclusiva la primera anotación gráfica que consta, no la primera real en el uso escrito, y, mucho menos, el uso oral de la voz, que siempre es anterior. En contraste, también existen representaciones parejas entre ambos idiomas, sin ser simétricas, como las del sonido que se hace al llorar, que en español es [buab buah] y, en inglés es [wah wab] y que, a nuestro entender, no tienen por qué representar un calco o una servidumbre necesaria del español hacia el inglés, sino una aproximación de ambos idiomas en la captacíon gráfica de un mismo sonido.

La onomatopeya surge del entorno oral, por lo que es un recurso del lenguaje, en cierto sentido, coloquial. A esta informalidad también se suma, como ya hemos mencionado, la dificultad de la captación fonética y gráfica, puesto que se trata de sonidos y ruidos que no corresponden a la articulación de una voz. Además, la onomatopeya se trata de una modalidad de expresión ciertamente básica, primitiva, popular o infantil, precisamente por la falta de rigor científico en la clasificación de sonidos inclasificables tanto para el oído como para el aparato fonador humano. Por lo tanto, se trata de una tarea casi imposible el tratar de decodificar sonidos ajenos al ámbito humano y codificarlos de nuevo en un sistema gráfico.

Cualquier sonido que se intente producir no será más que una leve aproximación al sonido fuente, por lo que la onomatopeya se asemeja a la metáfora en que se trata de una estructura bipolar en la que hay un origen o fuente (el sonido natural o artificial) y una voz meta: la captación irregular y aproximativa al sonido de origen extralingüístico. Una semejanza más con la metáfora consiste es que ambas surgen de un primitivo anterior: de carácter fonético en el caso de la onomatopeya, y de carácter icónico o conceptual en la metáfora. Así vemos cómo la onomatopeya tiene una naturaleza imitativa, al igual que la metáfora, por suponer ambas calcos de sonidos o de realidades que se desvirtúan apoyadas en una mínima coincidencia. Se trata, por lo tanto, de recursos de imitación, llamativos en sí por su propia naturaleza, pero imperfectos, porque aspiran a una realidad que jamás podrán aprehender. Asimismo, tanto la onomatopeya como la metáfora, con el paso del tiempo, pierden su fuerza, su valor imitativo o comparativo, de modo que existen algunas onomatopeyas de las que apenas percibimos su origen fonético, como puede ser la voz ululación.

Lógicamente, la metáfora (Bowdle y Gentner, 2005: 193-216; Pragglejaz, 2007: 1-39; Ruiz de Mendoza y Pérez Hernández, 2011: 1-25; Steen, 2008: 213241) recibe muchos más estudios que la onomatopeya, por ser más prolífica en la 
acuñación de voces. Del mismo modo, la didáctica de su adquisición (Batlle, 2014; Boers, 2014: 208-224; Cheikh-Kahmis, 2013; Ibarretxe-Antuñano, 2012; Vidiella, 2012) es objeto de innumerables análisis. La fuerza conceptual y retórica de las metáforas (Forceville y Urios-Aparisi, 2009) se halla en la cúspide del simbolismo léxico, pero también se dan otras formas figuradas de alto valor simbólico (Kristiansen et al., 2015). Tal es el caso de la personificación (que confiere a objetos, ideas o animales características humanas) y la animalización (que define al proceso inverso). Las dos pueden considerarse subtipos de metáforas. Así, al decir que el hombre es un lobo, le conferimos la atribución de peligrosidad, algo innato a los lobos. Con este proceder se dota de características animales a los seres humanos. Lo anterior, sin embargo, no implica que se considere al hombre como un animal (Eggetsson y Forceville, 2009: 429-450), sino tan solo que se le visiona desde una zona de características en intersección. Ambos procesos, personificación y animalización -que suelen estudiarse como parte de las metáforas (Ohkura, 2003: 56) - se dan tanto en el lenguaje literario como en el técnico. En este último, el propósito no es la creación de belleza y sí la descripción mediante semejanzas visuales o auditivas en la zona de intersección entre el hombre y el animal.

\section{CASO de ESTUdio y MÉtodo}

El léxico técnico recoge en su acervo expresiones de sonidos y ruidos para definir los fenómenos a los que se refieren. Para aproximarse a este fenómeno, en este estudio se realiza un análisis de ciertos elementos lingüísticos, los más comunes, que dan nombre y lexicalizan algunos sonidos de la ciencia y la tecnología: por ejemplo, se estudian las denominaciones para el ruido que producen los cables de alta tensión, las interferencias audibles en las transmisiones de radio y tv, o el ruido que producen las locomotoras y otras máquinas, entre otros. Como se ha mencionado, este estudio recoge solo las voces relativas al sonido y al ruido más comunes dentro de la ciencia y la tecnología, por lo que no pretende ser un análisis exhaustivo de dichos fenómenos, que tampoco son demasiado habituales en la formación de palabras. Del mismo modo, los campos técnicos objeto de estudio son los más prototípicos en cuanto al uso de las onomatopeyas. Así, para hablar de canto se establece una relación con los instrumentos musicales; del chasquido/parásito, con las telecomunicaciones; del craqueo, con la industria del automóvil; de la galería de susurros/sala de murmullos, con la arquitectura y la acústica; del tintineo/castañeteo, con los metales y la madera; de la ululación/chillido del búbo, con los ferrocarriles; y del zumbido, con las comunicaciones y la acústica. 
El objetivo de este trabajo es, a partir de una serie de voces, observar y mensurar la interacción entre el español y el inglés en este tipo de vocabulario especializado empleando para ello fuentes de artículos de diversa tipología en internet (webs divulgativas sobre arquitectura, consejos para aficionados a los coches, petroquímica especializada, normativa oficial sobre vocabulario electrotécnico, artículos divulgativos sobre los ruidos que produce el cuerpo humano, y una tesis sobre acústica) y diccionarios en papel y en línea, tanto generales (AHD, CD, DRAE, DUE, FD, Webster, WR) como técnicos (DAF, DITC, DPLEI). Algunos términos pertenecen tanto al lenguaje general como al técnico, sin embargo, otros se encuentran solo en el último, por tener un significado más restringido, como es el caso del compuesto galería de susurros/sala de murmullos, forma que no hemos encontrado en los diccionarios empleados y solo en un artículo de Internet .

La voces elegidas son: canto, chasquido/parásito, craqueo, galería de susurros/ sala de murmullos, tintineo/castañeteo, ululación/chillido del búho, y zumbido y sus correlatos ingleses singing/humming, hash/parasite, cracking, whispering gallery, chatter, hoot y hum. De esta selección lo primero que se desprende es que la sinonimia desempeña un papel primordial en las lenguas científico-técnicas, aspecto que se analiza para comprobar si los sinónimos pertinentes poseen un sentido y uso equivalente, es decir, si son sinónimos totales o absolutos. También a través del análisis, se procede a observar si los términos que captan sonidos vienen, bien de voces no figuradas, bien de onomatopeyas, como intento de captación de sonidos, o bien de metáforas o desvíos de sentido. Finalmente, de este escrutinio se produce la comparación entre ambos idiomas en el tratamiento de la lexicalización de los sonidos de la ciencia y la tecnología.

\section{RESUltados}

\subsection{Canto}

El DLE atribuye la acción de cantar a las personas o a los animales. Sin embargo, menciona el instrumento conocido como órgano y dice que tal caso es sinónimo de un canto figurado, compuesto de "notas diferentes en forma y duración". Por canto figurado, un modo de composición musical, se entiende el opuesto al canto gregoriano/cantus planus/canto llano, que no se acomodaba a distintos compases. Tal significado musical se extiende a los sublenguajes técnicos, por lo que se observa una migración de la lengua general al lenguaje técnico Así, en electrónica se habla del arco cantante (singing arc) y también del canto de los hilos eléctricos (bumming of 
the wires). El DAF dice que se llama arco cantante a uno eléctrico que oscila "entre dos electrodos de carbón, alimentados por corriente continua, formando parte ambos electrodos de un circuito". El DAF, asimismo, sostiene que el canto de los hilos eléctricos se refiere al zumbido y sonido del telégrafo y de los cables del teléfono en los postes de las calles, independientemente del viento que haya, como también señalan Ghose y Home (1994).

Mientras que el español hace alusión en todos los casos a la voz canto o su derivado cantante, el inglés escinde las opciones entre las formas singing y humming. El AHD refiere la capacidad del canto a las personas y a los pájaros, mientras que, con respecto a la voz humming (zumbido), de corte onomatopéyico, se refiere a un ruido prolongado y bajo, como el de las abejas, con lo que la referencia alude a un campo diferente del español. El aspecto en común consiste en que el inglés, tal cual hace el español técnico, elige formas figuradas (singing/humming) para calificar arcos e hilos eléctricos a los que se personifica atribuyéndoles capacidades que en principio pertenecen a personas o pájaros (como es el caso del canto), o a insectos (zumbido).

\subsection{Chasquido/parásito}

Chascar consiste en hacer un ruido con la lengua o con un látigo y tiene un origen expresivo, de intento de captación del sonido que produce tal movimiento, por lo que constituye una voz del lenguaje general. En radiocomunicaciones también se habla de chasquidos (hash), que equivalen a parásitos en pantalla (DITC). Sin embargo, el chasquido es un ruido seco y cortante. No obstante, los chasquidos no solo proceden de las máquinas, también los causan las neuronas y los huesos, porque el cuerpo humano emite ruidos de modo natural, como parte de su funcionamiento (Pérez, 2016). En contraste, como indica el FD, la voz hash del inglés se refiere al troceo o picado de la carne, con lo que nos encontramos ante la captación de un sonido mediante dos vías diferentes: el chas-chas de un látigo en español, y el hash-hash del cuchillo al ir troceando la carne en inglés.

Sin embargo, el ruido que producen las interferencias en la radio o la televisión es ligeramente diferente y más repetitivo, por lo que parece mejor término la denominación de estas interferencias bajo la forma parásitos. Como indica el DUE, tal voz tiene el étimo de huésped y se refiere en biología a organismos que viven a costa de otros, por lo que observamos el paso de una referencia al sonido en español e inglés (chasquido/hash) al hecho de vivir a costa de otros, también forma usada tanto en inglés como en español en calidad de calco del primero. Sin embargo, este significado primigenio de la biología se ha ampliado al del ruido molesto sin ninguna ventaja añadida a las comunicaciones. Observamos así como la ciencia también 
impregna de nuevas voces a la lengua general. Este sentido ha pasado a la lengua general para designar al que se aprovecha de otra persona, pero también a los lenguajes técnicos para designar el ruido que surge de modo natural, sin aportar nada beneficioso, en las transmisiones electrónicas. Se trata, por tanto, de una metáfora que capta la realidad desde un punto de vista ajeno al ruido. Este es el caso de la electrónica, donde las señales producen de forma natural interferencias que se conocen como parásitos. Estos, según indica la web http://www.aficionadosalamecanica.com/eliminacion-de-ondas-parasitas.htm, se deben a que el automóvil produce perturbaciones que hace falta eliminar para tener una correcta audición de la radio, ya que "todo aparato que lleve contactos en los cuales se producen chispas y que interrumpen el paso de corriente de forma brusca, es motivo y causa de producción de ruidos parásitos". Asimismo, parásitos se explica como ruido natural o artificial, como sinónimo de industrial, mientras que chasquido se define como una perturbación de tipo electromagnético ( NOM-063-SCT1-1993).

\subsection{Craqueo}

En los motores de combustión interna, se emplea el anglicismo aclimatado craqueo, procedente del inglés cracking, que designa un proceso en el que ciertos hidrocarburos se descomponen a causa del calor (Webster), aunque en origen esta voz se refería fundamentalmente a la madera ya que alude al ruido producido por el resquebrajamiento de esta, pero no, en principio, a su rotura. Sin embargo, en la web petroquimicaperu.blogspot.com/2011/07/proceso-de-craqueo.html se indica que en la industria del petróleo y en la química, el craqueo es el proceso por el cual se rompen (craquean) moléculas orgánicas.

También, el WR indica que se trata de un ruido repentino y agudo causado por la separación de las partes de un objeto, puesto que al requebrajamiento extremo le puede seguir el desgajamiento de las piezas. Así, la onomatopeya crack origina los derivados anglizantes crac y craquear, el primero de origen onomatopéyico puro. Es decir, se trata de un anglicismo que han adoptado principalmente la técnica y la economía y que, como ha sido importado directamente del inglés técnico extiende su significado al de rotura, al contrario de lo que hace el inglés general, en que tal término tiene como primer significado el de resquebrajamiento sin separación de las partes (WR) para extenderse, en una segunda acepción, al desprendimiento de las partes de la pieza. Se trata, en consecuencia, de una onomatopeya que refleja un fenómeno producido por un agrietamiento que se ha ampliado semánticamente para acuñar nuevos significados en una relación causa-consecuencia: del resquebrajamiento y su sonido correspondiente se pasa a la consecuencia del desprendimiento o de la liberación. 


\subsection{Galeria de susurros/sala de murmullos}

En acústica se emplean los compuestos sinónimos galería de susurros y sala de murmullos (whispering gallery). En efecto, como apunta Alexandre (2011), "Las galerías de susurros son curiosidades acústicas que se producen en recintos abovedados o con paredes con forma cóncava. Así, en cúpulas grandes, la energía sonora se retrasa y aparece el eco (Redonda, 2013: 39). El efecto que se produce es que cuando una persona susurra en un punto de la sala, este susurro es apenas audible para puntos cercanos a este hablante, pero un oyente situado en ciertos puntos de la sala será capaz de escuchar perfectamente el sonido emitido". Observamos en este caso cómo el español calca del compuesto inglés y ambos pertenecen en exclusiva al lenguaje técnico. Se trata de un sonido de efecto rebote solo a puntos lejanos debido a la geometría de un edificio. En este caso, los susurros o murmullos no son figurados o metafóricos, sino reales, puesto que se refiere a sonidos auténticos que se trasladan de un punto a otro de la arquitectura de una construcción.

\subsection{Tintineo/castañeteo}

Tintineo o casteñeteo (chatter) es el ruido producido por una herramienta cuando está floja. El tintineo es un sonido similar al de una campana que suena débilmente, y deriva de tintín, como indica el DUE. El castañeteo, en contraste, se trata de un sonido que se asemeja al de las castañuelas o al de los dientes al chocar entre sí. El CD atribuye la capacidad de charla (chatter) a las personas y a ciertos animales, como los pájaros o los monos, cuando parece que imitan la producción de sonido humano en charlas de tono rápido e informal. La forma chat procede de chatter, palabra asociada con las onomatopeyas de producción de sonido humano o animal, por asemejarse este al sonido que producen las charlas de los humanos. Sin embargo, este diccionario también atribuye al mismo sustantivo la capacidad de choque de los dientes entre sí. Es decir, también alberga parte del significado que en español pertenece a la forma castañeteo, más no su totalidad puesto que el sentido del repique de la madera queda fuera de su alcance. Por lo tanto, mientras que tintineo es un derivado de la onomatopeya tintín, la cual intenta capturar un ruido metálico, la forma castañeteo no procede del intento de la captación del sonido de la madera al chocar entre sí, sino que es una metáfora que procede de castaña (DUE) debido al color, forma y tamaño de las piezas. 


\subsection{Ululación/chillido del búbo}

Al silbido de la locomotora (hoot) también se le conoce por ululación o chillido del búho (DPLEI). Este último término constituye una animalización, por atribuirse características de un ser vivo, un animal, a una máquina. Mientras que un silbido se produce por el paso del aire a través de un cuerpo hueco y, en consecuencia, tanto humanos como máquinas pueden silbar, la ululación es un tipo de ruido diferente, más concreto y solo relativo a los búhos. Se puede decir que la primera forma, silbido, es más genérica puesto que existen muchos tipos de silbido, desde el humano hasta el producido por la infiltración del aire en cualquier ente hueco. El inglés recoge exactamente los mismos significados que el español al incluir el sentido de chillido y el de ululación bajo la voz hoot. En consecuencia, ambos idiomas emplean una onomatopeya relativa al sonido que produce el búho (ul, ul/hoot, hoot) que lleva a la animalización de la máquina, puesto que se conceden características de un ser vivo a un objeto inanimado. De este modo, pasa esta voz del lenguaje general al técnico, calcando de un sonido de la naturaleza y atribuyéndolo a una máquina. Cabe señalar a este respecto que un tren o locomotora, sin embargo y precisamente por su capacidad de movimiento, de emanación de ruido y de vapor, parece tener vida y ser un gusano ciempiés, con sus ruedas que parecen pequeñas patas.

\subsection{Zumbido}

El DLE señala que zumbar consiste en "producir ruido o sonido continuado y bronco, como el que se produce a veces dentro de los mismos oídos". Se trata de una captación indefinida del ruido, que indica que se oye un zumbido raro o un sonido incierto. En realidad, se trata de la representación onomatopéyica del ruido que producen las abejas al batir las alas (zum-zum) y que en inglés se capta de modo diferente (bum-hum). En la radio y en acústica también se habla de zumbidos (bums), por similitud con el ruido que producen las abejas, que no son más que interferencias que pueden aumentar según se sube el volumen. Se trata de una onomatopeya tanto en inglés como en español, lengua que calca de la primera como acuñadora de la ciencia y la tecnología.

\section{Discusión}

A continuación se ofrecen esquematizados los resultados más significativos del análisis de las voces, para proceder seguidamente a su comentario: 


\begin{tabular}{l|ll|}
\hline Español & Canto/cantante & Personificación \\
Inglés & Singing & Personificación \\
\cline { 2 - 3 } & Humming & Onomatopeya/Animalización \\
\cline { 2 - 3 }
\end{tabular}

Tabla 1. Canto

Observamos en la Tabla 1 cómo las voces españolas, con alternancia de forma sustantiva según se refieran al hecho o a la acción, suponen metáforas puesto que se asimila el sonido producido por un órgano con el procedente de la voz humana. Por otro lado, también constituyen personificaciones cuando se aplica a animales u objetos una capacidad que, en principio, solo poseen las personas.

Con respecto a los correlatos ingleses, se debe hacer una escisión entre los dos sinónimos dado que el primero, singing, de acoplamiento perfecto con su correlato español, supone una personificación por los motivos que se mencionan arriba, mientras que su alternativa, humming, representa una onomatopeya y una animalización, por ser un intento de captación de un sonido continuo, similar al del aleteo de las abejas, lo que en castellano sería un zumbido.

\begin{tabular}{|l|ll|}
\hline Español & Chasquido & Onomatopeya \\
\cline { 2 - 3 } Inglés & Parásito & Animalización \\
\cline { 2 - 3 } & Hash & Onomatopeya \\
\cline { 2 - 3 } & Parasite & Animalización \\
\cline { 2 - 3 }
\end{tabular}

Tabla 2. Chasquido

En la Tabla 2 observamos cómo el español y el inglés se escinden ambos en una dicotomía dual, en la que se encuentra por un lado la onomatopeya, y, por otro lado, la metáfora. La primera dicotomía llama la atención sobre la diferente captación del sonido en ambos idiomas, porque, aunque se trata de un fenómeno universal, cada lengua refleja el sonido de modo caprichoso, precisamente por la dificultad de captura de fenómenos que escapan al ámbito de las palabras: así, lo que en español se muestra como chas, en inglés se convierte en hash para tratar de reproducir el ruido que produce un látigo al batirse o un cuchillo al trocear carne, sonidos cortantes ambos.

En cuanto a la captación de un sonido prolongado, ambas lenguas, junto con el francés, hacen uso de la misma metáfora. Así, la metáfora que se usa se relaciona con 
la cohabitación de dos o más organismos habiendo siempre al menos uno que vive a costa de los demás sin aportar ningún beneficio. Con esto comprobamos cómo una voz específica de la biología ha migrado a otros campos técnicos y, también, a la lengua general. Por tanto, el proceso de lexicalización de los sonidos de la ciencia y la tecnología no siempre se importa desde la lengua general: existen casos en que se da el trayecto inverso y la lengua de especialidad impregna de significados nuevos otras técnicas, lo que da lugar a la polisemia técnica, e, incluso, se trasvasa a la lengua general, a la que enriquece. Del mismo modo, resulta casi imposible encontrar la fecha de la aparición primera de la voz, puesto que algunos diccionarios ofrecen tan solo el primer registro gráfico del que tienen constancia, lo que no significa que sea el uso primigenio auténtico que casi con total seguridad debió de nacer del lenguaje oral.

\begin{tabular}{l|ll|}
\hline Español & Craqueo & Onomatopeya/Metáfora \\
Inglés & Cracking & Onomatopeya/Metáfora \\
\cline { 2 - 3 } & &
\end{tabular}

Tabla 3. Craqueo

En la Tabla 3 vemos que ambos idiomas emplean una onomatopeya que refleja el ruido que hace la madera cuando se resquebraja, por lo que en principio se parte de un sonido. Dicho proceso de agrietamiento puede derivar en el desgajamiento de las piezas, y no solo las de madera, sino de cualquier material, por lo que lo que comenzó como onomatopeya ha evolucionado a una metáfora de causa-consecuencia, dado que se finaliza con una escisión. Tanto el español como el inglés reflejan dicho proceso de modo idéntico.

\begin{tabular}{l|ll|}
\hline Español & Galería de susurros/murmullos & Ametáfora \\
Inglés & Whispering gallery & Ametáfora \\
\cline { 2 - 3 } & &
\end{tabular}

Tabla 4. Susurro

En el compuesto galería de susurros/whispering gallery ambos idiomas siguen la misma pauta y echan mano de voces no desviadas puesto que el compuesto se refiere a susurros o murmullos reales y no figurados que se proyectan en distintos ángulos de edificios de geometría particular. 


\begin{tabular}{l|ll|}
\hline Español & Tintineo & Onomatopeya \\
& Castañeteo & Metáfora \\
\cline { 2 - 3 } Inglés & Chat & Onomatopeya/Personificación \\
\cline { 2 - 3 } & &
\end{tabular}

Tabla 5. Castañeteo

La Tabla 5 recoge el juego de sinónimos españoles que confluyen en la forma inglesa chat. La voz tintineo es una onomatopeya que procede del sonido del metal al chocar entre sí, mientras que su sinónimo castañeteo es una metáfora de castaña que recoge el sonido de las piezas de madera, como el de las castañuelas, o el de los dientes al chocar entre sí. Ambas formas del español se unen en la voz del inglés chat, que representa una onomatopeya que recoge tanto el sonido de las charlas de humanos como de animales, y el de los dientes al castañetear. En tal caso una misma realidad se percibe desde perspectivas diferentes en ambas lenguas, puesto que el español simplemente recoge el choque de los dientes, mientras que el inglés les atribuye una especie de capacidad de charla o diálogo entre ellos al definir tal movimiento y ruido bajo el término $c h a t$.

\begin{tabular}{l|ll|}
\hline Español & Silbido & Ametáfora \\
\cline { 2 - 3 } & Ululación & Onomatopeya/Animalización \\
\cline { 2 - 2 } Inglés & Chillido del búho & Animalización \\
\cline { 2 - 3 } & Hoot & Onomatopeya/Animalización \\
\cline { 2 - 3 }
\end{tabular}

Tabla 6. Ululación

En la Tabla 6 comprobamos cómo tres sinónimos españoles convergen en una misma palabra del inglés. El significado se refiere en todos los casos al ruido que hace una locomotora cuando expulsa aire por la chimenea. El término silbido es el más aséptico puesto que se refiere tanto a personas como a máquinas ya que solo implica el paso del aire por una cavidad y su correspondiente ruido. En contraste, la forma ululación aplicada a una máquina supone, aparte de una onomatopeya procedente del sonido que hace el búho o ululación, una metáfora que pone a un objeto en el lugar de un ser vivo, por lo que lo personifica al dotarle de vida. El tercer sinónimo, chillido del búho, asimismo, supone otra animalización ya que atribuye de nuevo capacidades de un ser vivo a una locomotora. 
El inglés, en contraste, unifica los tres sinónimos españoles en una forma, hoot, correlato exacto de ululación, y, por lo tanto, onomatopeya. Además, al incorporar un sentido oblicuo, por conceder capacidades de ser vivo a una máquina también supone una animalización.

\begin{tabular}{l|ll|}
\hline Español & Zumbido & Onomatopeya/Animalización \\
Inglés & Hum & Onomatopeya/Animalización \\
\cline { 2 - 3 } & &
\end{tabular}

Tabla 7. Zumbido

Las voces zumbido y humming son correlatos perfectos que reflejan la captación de un sonido continuo e indefinido que retumba en los oídos. El significado de la voz se extendió del ruido que hacen las abejas al batir sus alas a cualquier sonido prolongado, monótono y pesado, por lo que supone una metáfora en ambos idiomas.

\section{Conclusiones}

Del estudio contrastivo de las voces canto, chasquido/parásito, craqueo, galería de susurros/sala de murmullos, tintineo/castañeteo, ululación/chillido del búbo, y zumbido y sus correlatos ingleses singing/humming, hash/parasite, cracking, whispering gallery, chatter, hoot y hum se desprende que el español emplea 11 voces, mientras que el inglés solo 9 para definir los mismos fenómenos, lo que revela un mayor número de sinónimos, de significantes diferentes, en nuestra lengua para referirse a un mismo significado. Algunos de estos sinónimos pueden considerarse como sinónimos totales, como es el caso de ululación y chillido del búho. Otros, en contraste, si bien designan una misma realidad, lo hacen apuntando a una perspectiva diferente, como es el caso de chasquido/parásito, tintineo/castañeteo y silbido. En estos casos, la significación es idéntica pero los significantes apuntan a conceptos diferenciados que acaban convergiendo en una misma realidad. Además, el español muestra 7 modelos distintos en la acuñación de términos relativos a la emanación de ruido o sonido: ametáfora 2 , metáfora 1 , personificación 1 , animalización 2 , onomatopeya 2, onomatopeya con metáfora 1, y, onomatopeya con animalización 2 .

En contraste, el inglés muestra otros 7 modelos o patrones en la lexicalización del sonido, faltándole la variante de metáfora pura: metáfora 1 , personificación 1 , animalización 1 , onomatopeya 1 , onomatopeya con metáfora 1 , onomatopeya con personificación 1, onomatopeya con animalización 3 . 
Así, el estudio de las 11 voces del español revela una presencia de un 18,18\% de ametáforas, un 9,09\% de metáforas, otro 9,09\% de personificaciones, un 18,18\% de animalizaciones, otro 18,18\% de onomatopeyas, un 9,09\% de onomatopeyas con metáfora, y un 18'18\% de onomatopeyas con animalización.

En contraste, el análisis de las 9 voces del inglés muestra un $11,11 \%$ de ametáforas, otro $11,11 \%$ de personificaciones, un $11,11 \%$ de animalizaciones, otro $11,11 \%$ de onomatopeyas simples, otro 11,11 de onomatopeyas con metáfora, otro $11,11 \%$ de onomatopeyas con personificación y un 33,33\% de onomatopeyas con animalización.

El estudio revela que las tipologías de acuñación léxica en lo relativo a la captación de sonido en ambos idiomas están muy fragmentadas si atendemos a los subtipos. De la comparación de estadísticas se desprende que, en lo que respecta a la captación del sonido con uso de onomatopeyas, este mecanismo pesa más en el inglés (66\%) que en el español (42\%).

Para finalizar, se muestra al español como una lengua más abundante en sinónimos que el inglés en lo que concierne a la representación de sonidos, mientras que el inglés en lo que destaca es por el flujo superior de onomatopeyas puras o mixtas, lo que revela al inglés como una lengua más tendente que la española a la acuñación de un léxico que refleje en su misma morfología el sonido del que procede, de resonancias animales en muchos casos. Además, tal recurso casa perfectamente con la acuñación de monosílabos, más propios del inglés que del español.

\section{REFERENCIAS}

Álvarez de Miranda, Pedro (2009): Onomaturgia, Centro Virtual Cervantes, Rinconete. En línea:<https://cvc.cervantes.es/el_rinconete/anteriores/ noviembre_09/04112009_01.htm> [16/04/2021]

BATLle, Jaume (2014): «En el amor y en la guerra: una unidad didáctica para el desarrollo de la competencia metafórica», Jornadas pedagógicas de ELE, Valencia, Educaspain.

Boers, F. (2014): «Cognitive linguistic approaches to teaching vocabulary: assessment and Integration», Language Teaching, 46, pp. 208-224.

Bowdle, Brian F. y Dedre Gentner (2005): «The career of metaphor», Psychological Review, 112, pp. 193-216.

Bueno, Maria Lourdes (1994): «La onomatopeya y su proceso de lexicalización: notas para un Estudio», Anuario de Estudios Filológicos XVII, Cáceres, UEx, pp. 15-26. 
Cheikh-Kahmis Cases, Fátima (2013): Lingüistica cognitiva aplicada a la enseñanza del léxico en segundas lenguas. Las colocaciones en clase de ELE, Memoria de Máster, Universidad a distancia, RedEle.

Eggertsson, Gunnar y Charles Forceville (2009): «Multimodal Expressions of the HUMAN VICTIM IS ANIMAL metaphor in horror films», en Charles J. Forceville y Eduardo Urios-Aparisi (eds.). Multimodal Metaphor Series:Applications of Cognitive Linguistics, 11, Berlin, De Gruyter Mouton, pp. 429-450.

Elvira, Javier (2006): «Aproximación al concepto de lexicalización», Diacronía, lengua española y lingüistica: Actas del IV Congreso Internacional de la Asociación de Jóvenes Investigadores de Historiografia e Historia de la Lengua Española, pp. 21-42.

ForCeville, Charles y Eduardo Urios-Aparisi (eds.). (2009): Multimodal Metaphor Series: Applications of Cognitive Linguistics, 11, Berlin, De Gruyter Mouton.

IBARRETXE-ANTUÑANO, Iraide y Javier VALENZUELA (2012): Lingüistica cognitiva, Barcelona, Anthropos.

Kristiansen, G., René Dirven y Francisco José Ruiz de Mendoza (2015): Applications of Cognitive Linguistics, Berlín, De Gruyter Mouton.

Moreno-CABrera, Juan Carlos (1998): «Sintaxis formal y sintaxis conceptual: más allá de la tipología de las oraciones de relativo», Syntaxis: An international journal of syntactic research, 1, pp. 63-92.

OkHura, Chiaki (2003): «The semantics of metaphor in the Game Theoretic Semantics with at least two coordination equilibria », LexFig '03: Proceedings of the ACL Workshop on Lexicon and Figurative Language, 14, pp. 56-63.

Pragglejaz Group (2007): «MIP: A method for identifying metaphorically used words in Discourse», Metaphor and Symbol, 22, pp. 1-39.

REDONDA, Martín (2013): Acústica aplicada a la edificación : evolución histórica desde la Antigüedad hasta su actual integración en los procesos constructivos, Trabajo Fin de Grado. Universidad de La Coruña. En línea: https://ruc.udc.es/dspace/ handle/2183/10113 [27/09/2021

Ruiz de Mendoza, Francisco José y Lorena Pérez Hernández (2011): «The contemporary theory of metaphor: Myths, developments and challenges», Metaphor and Symbol, 26, pp. 1-25.

STEEN, Gerard (2008): «The paradox of metaphor: Why we need a three-dimensional model of Metaphor», Metaphor and Symbol, 23, 4, pp. 213-241.

Vidiella, Mercé (2012): El enfoque léxico en los manuales de ELE, Memoria de Máster, Suplementos MarcoELE 14. 


\section{Fuentes}

Alexandre, E. Galerias de los susurros. En línea: < http://construirunmundonuevo.com/construccion/las-galerias-de-los-susurros $>$ [1/03/2021]

Antiparasitaje del automóvil - Aficionados a la mecánica. En línea: <http:// www.aficionadosalamecanica.com/eliminacion-de-ondas-parasitas.htm > [4/04/2021].

Beigdeber, Francisco (2008): Diccionario Politécnico de las Lenguas Española e Inglesa, Madrid, Díaz de Santos.

Collins Dictionary. En línea: < https://www.collinsdictionary.com/es> [15/04/2021].

Free Dictionary. En línea: <https://es.thefreedictionary.com> [15/04/2021].

Ghose, Partha y Dinkanpar Home (1994): Riddles in Your Teacup, Amazon, 139.

Ingenieria Petroquimica: Proceso de Craqueo. (2011): En línea: <http://petroquimicaperu.blogspot.com/2011/07/proceso-de-craqueo.html> [15/04/2021].

León, Mario (2004): Diccionario de Informática, Telecomunicaciones y Ciencias, Díaz de Santos/Babel.

Levy, Elie (2004): Diccionario Akal de Física, Ediciones Akal.

Moliner, María (2013): Diccionario de Uso del Español, Madrid: Gredos.

Merrian-Webster Dictionary. En línea: <https://www.merriam-webster.com> [15/04/2021].

Norma Oficial Mexicana NOM-063-SCT1-1993 sobre "Vocabulario electrotécnico parte 5. Perturbaciones radioeléctricas". (12-07-94): En línea: <https:// iaconsma.com/oficina_virtual/normatividad/NOM-063-SCT1-1993.pdf> [29/09/2021].

PÉreZ, A. (7 de marzo de 2016), «¿Sabíais que nuestro cuerpo no para de hacer ruidos?». En línea: <https://www.quo.es/salud/g54183/ruidos-del-cuerpo-humano $>[15 / 04 / 2021]$.

Real Academia Española. Diccionario de la lengua española. En línea: < https://dle.rae.es> [6/04/2021].

The American Heritage Dictionary of the English Language. En línea: <https://ahdictionary.com $>[6 / 04 / 2021]$.

Wordreference. En línea: <https://www.wordreference.com> [16/04/2021].

\section{Abreviaturas}

AHD The American Heritage Dictionary of the English Language.

CD Collins Dictionary. 
DAF Diccionario Akal de Física.

DITC Diccionario de Informática, Telecomunicaciones y Ciencias.

DPLEI Diccionario Politécnico de las Lenguas Española e Inglesa.

DLE Diccionario de la Lengua Española.

DUE Diccionario de Uso del Español.

FD Free Dictionary.

NOM-063-SCT1-1993 Norma Oficial Mexicana NOM-063-SCT1-1993 sobre "Vocabulario electrotécnico parte 5. Perturbaciones radioeléctricas".

Webster. Merrian-Webster Dictionary.

WR Wordreference.

NOTA: Agradezco al equipo de la revista Anuario de Letras sus valiosas observaciones en la presentación de contenidos de este artículo.

Fecha de recepción: 23 de abril de 2021 Fecha de aceptación: 4 de noviembre de 2021 